(2) Open Access Full Text Article

REVIEW

\title{
Exosome: A Review of Its Classification, Isolation Techniques, Storage, Diagnostic and Targeted Therapy Applications
}

This article was published in the following Dove Press journal: International Journal of Nanomedicine

\section{Yi Zhang \\ Jiayao $\mathrm{Bi}$ \\ Jiayi Huang ip \\ Yanan Tang \\ Shouying Du \\ Pengyue Li (D) \\ School of Chinese Materia Medica, Beijing University of Chinese Medicine, Beijing, \\ People's Republic of China}

Correspondence: Pengyue Li

Email lipengyuetougao@I26.com

\begin{abstract}
Exosomes are nano-sized small extracellular vesicles secreted by cells, carrying nucleic acids, proteins, lipids and other bioactive substances to play a role in the body's physiological and pathological processes. Compared to synthetic carriers such as liposomes and nanoparticles, the endogeneity and heterogeneity of exosomes give them extensive and unique advantages in the field of disease diagnosis and treatment. However, the storage stability, low yield, low purity, and weak targeting of exosomes limit its clinical application. For this reason, further exploration is needed to optimize the above problems and facilitate future functional studies of exosomes. In this paper, the origin, classification, preparation and characterization, storage stability and applications of exosome delivery system are summarized and discussed by searching a large number of literatures.
\end{abstract}

Keywords: exosomes, extraction and purification, storage stability, biomarkers, targeted drug delivery, surface modification

\section{Introduction}

Exosomes, with a diameter of about 40-100nm, are biological nanoscale spherical lipid bilayer vesicles secreted by cells, floating at a density of $1.13-1.19 \mathrm{~g} \cdot \mathrm{mL}^{-1}$ in a sucrose density gradient solution. ${ }^{1-5}$ In 1981, Trams et al ${ }^{6}$ collectively referred to plasma membrane-derived vesicles as exosomes and first proposed the concept of "exosomes", which was regarded as membrane vesicles with 5'-nucleotide enzyme activity that may have physiological functions and originate from the exudation of various cell line cultures. The currently defined exosomes $(40-100 \mathrm{~nm})$ were first found in sheep reticulocytes in 1983. ${ }^{7,8}$ Johnstone et al $^{9}$ tracked transferrin receptors during the maturation of reticulocytes and found that the formation of exosomes is the mechanism for the loss of transferrin receptors in mature red blood cells. To distinguish them from other types of extracellular vesicles (EVs), they were named exosomes. However, it's worth noting that the term "exosomes", even if widely used, has been suggested to be replaced by the term "small Extracellular Vesicles (sEVs)" according to ISEV 2018 guidelines, ${ }^{10}$ due to methodological difficulties of separation. Studies have found that exosomes contain nucleic acids, proteins, lipids, cytokines, transcription factor receptors and other bioactive substances. ${ }^{11,12}$ Among them, exosomal protein components are mainly divided into two categories, one is the public components, which participate in the process of vesicle formation and secretion, that is, exosomes are ubiquitous, including membrane transport and fusion- 
related proteins (like Rab, GTPases), Heat shock proteins (like HSP70, HSP90), four-transmembrane protein superfamily (like CD63,CD81), ESCRT complex-related proteins (like Tsg101, Alix), integrins, etc.; the other one is specific components, which are closely related to their progenitor cells, that is, cell-specific, such as CD45 and MHC-II derived from antigen-presenting cells. With the in-depth study of exosomes, its applications are becoming more and more widespread. Exosomes can play a role in physiological and pathological processes, acting as mediators for intercellular communication and material exchange. At the same time, exosomes can deliver a variety of bioactive substances and easy-to-deactivate or easily degradable ingredients (referring to therapeutic agents that have a short retention time in the body when administered alone) through multiple pathways and sites, and safely transfer them to target cells to participate in regulation, such as tissue repair, tumor diagnosis and treatment, and immune regulation. ${ }^{5,13}$ In this review, we mainly focus on the classification, preparation and characterization of exosomes, storage stability, biomarkers, targeted drug delivery systems and provide some insights.

\section{Origin and Classification of Exosomes}

\section{Formation}

The initial endosomes are formed by the invagination of the cell membrane in the early stage, and then the bioactive substances begin to accumulate in the early sorting endosomes (ESEs). Then, under the control of the endocytosis sorting complex and other related proteins required for transport, the early endosomes become late sorting endosomes (LSEs). LSEs ultimately form multivesicular bodies (MVBs) after a second indentation. After MVBs fuses with the cell membrane, the substances inside the cells are released to the outside in the form of vesicles. These vesicles are exosomes. The biological origin of exosomes is shown in Figure 1. The formation of exosomes is diversified. At present, more researches are on ESCRT-dependent and ESCRT-independent mechanisms. ${ }^{14-16}$ However, it has recently been reported that certain components, such as four-transmembrane domain proteins and lipid raft, are also involved in the formation of some exosomes. ${ }^{17,18}$ Therefore, the exact mechanism remains controversial.

\section{Classification}

Exosomes are divided into natural exosomes and engineered exosomes based on whether they have been artificially modified. Ulteriorly, natural exosomes are divided into animalderived exosomes and plant-derived exosomes. Because exosomes are produced under normal and tumor conditions, animal-derived exosomes are further divided into normal exosomes and tumor exosomes.

Almost all types of normal cells can produce exosomes, like human umbilical vein endothelial cells, mesenchymal stem cells (MSC), T cells, B cells, macrophages, dendritic cells (DC), natural killer (NK) cells. ${ }^{19-22}$ For example, mesenchymal stem cells (MSCS) are pluripotent stem cells capable of self-renewal and multidirectional differentiation. MSCs can not only adapt to the tumor microenvironment, but also have powerful paracrine activity and secrete a large number of exosomes. Studies have demonstrated that

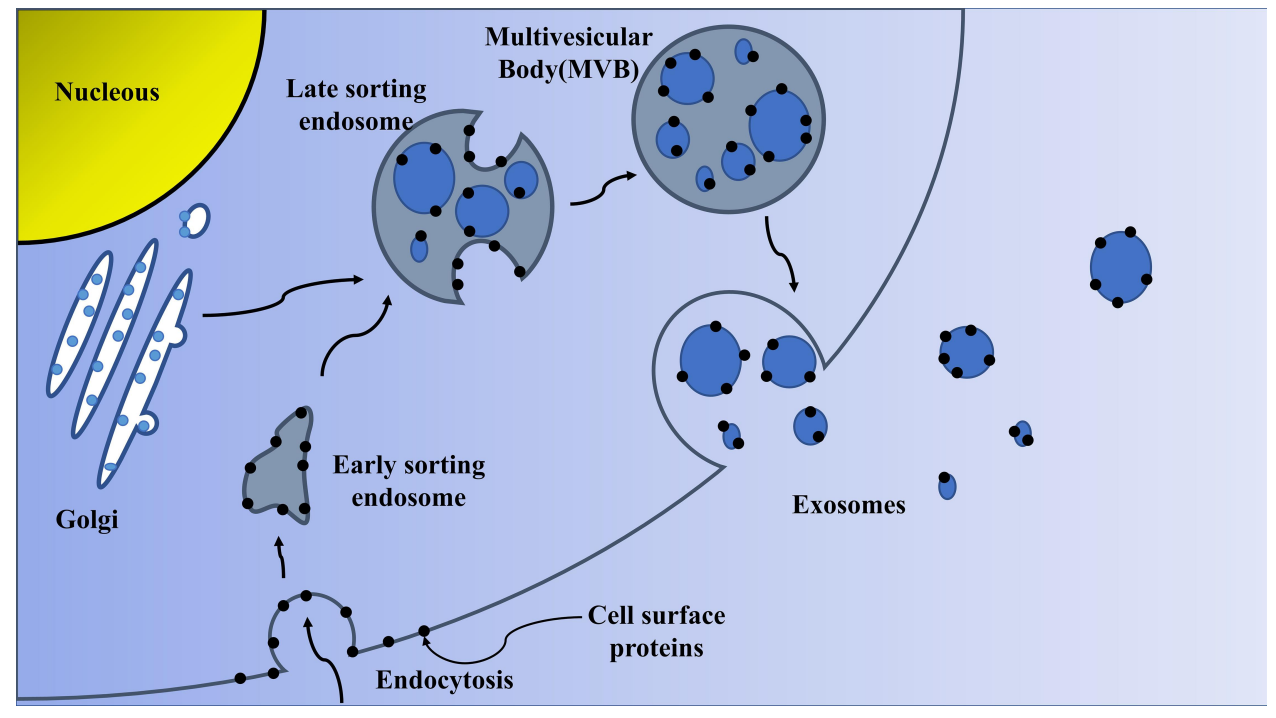

Figure I Biogenesis of exosomes. 
paclitaxel (PTX) -containing exosomes have a significant inhibitory effect on the proliferation of the human pancreatic cancer cell line CFPAC-1 in vitro and have the potential to act as drug carriers. ${ }^{23}$ In addition, MSC exosomes have been shown to play a role in the development of many diseases. They not only participate in the process of tissue repair and injury, ${ }^{24,25}$ and have certain therapeutic effects on cardiovascular diseases (like myocardial infarction) ${ }^{26,27}$ and neurological diseases, ${ }^{28}$ but also can alleviate liver injury and be used in the treatment of liver diseases. ${ }^{29}$ Macrophages are mononuclear phagocytes, which play a role in inflammation, immune regulation, wound healing, and angiogenesis. ${ }^{30}$ Generally, macrophages are widely distributed in the body and can be polarized into M1 or M2 macrophages. Research has shown that macrophage-derived exosomes can affect the lung tissue microenvironment by affecting inflammatory signals and immune function. ${ }^{31}$ In additional, Exo-PTX has a significant anti-tumor effect in the Lewis lung cancer metastasis model. The macrophage-derived exosomes delivered via the respiratory pathway are almost completely co-located with the metastasis of cancer cells, which suggests that exosomes derived from macrophages may have specific surface proteins and tend to accumulate in the cancer cells preferentially, and the specific mechanism remains to be further investigated. ${ }^{32}$ Exosomes are able to inherit many specific biomolecules from parent cells, which is one of the reasons for their heterogeneity. ${ }^{33}$ Not only that, there are some differences in the exosomes from different sources in terms of yield, contents, function, drug loading. As a result, different therapeutic effects may be produced. Kanchanapally et al ${ }^{34}$ used co-incubation to successfully load doxorubicin (DOX) onto pancreatic stellate cells (PSCs), pancreatic cancer cells (PCCs) and macro-phage-derived exosomes. By contrast, exosomes derived from PSCs have the highest yield and high drug loading rate, while macrophagederived exosomes have the strongest antitumor activity, indicating the specificity of exosomes from different sources.

Also, normal exosomes mentioned above can be widespread in biofluids, such as saliva, plasma, urine, ascites, milk and bile. Currently, milk-derived exosomes have been successfully developed to deliver the chemotherapeutic drug paclitaxel, and the bioavailability, stability, safety and toxicity have been tested to meet standards. ${ }^{35}$ Similarly, exosomes present in biofluids can express certain diagnostic and therapeutic properties. For example, in-depth study of circRNAs in exosomes present in blood or cerebrospinal fluid can contribute to reveal the underlying mechanisms of the development of neuropsychiatric disorders ${ }^{36}$. Furthermore, miRNAs carried by serum exosomes can be used for the diagnosis and prognosis of spinal cord injury (SCI) ${ }^{37}$. Likewise, by evaluating the expression profile of miRNAs in endometrial cancer (EC) and urine-derived exosomes from suspected patients, it was found that differentially expressed miRNAs can be used as biomarkers for EC diagnosis. ${ }^{38}$

Tumor cells can secrete a large number of exosomes, and the specific antigens on their surface can reflect the nature of donor cells. Therefore, tumor exosomes have attracted great attention in cancer research. Tumor exosomes not only play an important role in the process of tumor growth, metastasis, and immune regulation, ${ }^{39,40}$ but also monitor the development of diseases ${ }^{41}$ and serve as diagnostic markers for diseases. ${ }^{42}$ For example, $\mathrm{Wu}$ et $\mathrm{al}^{43}$ found that colorectal cancer (CRC) cellderived exosomes overexpressing CAPS1 can enhance the migration of normal colonic epithelial FHC cells. Therefore, inhibiting the secretion of tumor exosomes is a treatment option for patients with metastatic CRC. A study showed that TKIs are tyrosine kinase inhibitors targeting BCR-ABL1 p210 oncoprotein and have significant therapeutic effects on Philadelphia chromosome-positive chronic myeloid leukemia $(\mathrm{Ph}+\mathrm{CML})$. The tumor exosomes in TKI-treated patients in the chronic phase of CML can identify the persistence of residual active leukemia cells which cannot be evaluated by the current standardized MRD monitoring system, and can be used as a new monitoring tool to prevent CML recurrence in the future. ${ }^{41}$

In addition, food-derived exosomes also have good development prospects. In recent years, studies have found that plant-derived exosome-like nanoparticles (ELN) have similar structures to mammalian exosomes. Ginger-derived particles can prevent the development of liver-related diseases, and ELN derived from grapes, carrots, grapefruit and ginger have anti-inflammatory effects and can maintain intestinal homeostasis. $^{44-47}$

At present, exosomes are classified mainly on the basis of sources. This classification does not analyze the characteristics and functional applications of various types of exosomes in detail. In the future, further subdivisions from the aspects of organophilicity, biological distribution and immunogenicity may be considered. ${ }^{29}$

\section{Preparation and Characterization Isolation}

With the in-depth study of exosomes, its potential application value has been continuously tapped. Reproducible isolation and enrichment of exosomes will help assess their biological functions. However, exosomes are heterogeneous in size, 
content, function and source, ${ }^{33}$ which makes isolation difficult. Moreover, most current isolation technologies cannot completely separate exosomes from lipoproteins with similar biophysical characteristics and extracellular vesicles derived from non-endosomal pathways, resulting in low exosomal purity. Therefore, how to efficiently enrich exosomes is a major issue currently, which is crucial for downstream analysis of exosomes. For different purposes and applications, different isolation methods are selected, among which ultracentrifugation, size-based isolation techniques, polymer precipitation, immunoaffinity capture techniques are more commonly used.

\section{Ultracentrifugation Techniques}

Ultracentrifugation (UC) is currently the most widely used isolation technique and is also known as the gold standard for exosome extraction and separation. UC mainly harvests the required components based on the size and density differences of each component in the original solution, so it is suitable for the separation of large-dose sample components with significant differences in sedimentation coefficient. ${ }^{48}$ Johnstone et al first applied this method to isolate exosomes in tissue culture medium of reticulocyte, and the method was optimized by Thery et al. ${ }^{9,49}$ The ultracentrifugation is mainly divided into two steps: firstly, a series of continuous low-medium speed centrifugation to remove dead cells, cell debris and large-size extracellular vesicles, and then to separate exosomes at a higher speed with a centrifugal force of $100,000 \times \mathrm{g}$, the exosomes were washed with PBS to remove impurities such as contaminating proteins. Studies have found that centrifugation time, centrifugal force, rotor type and parameters all affect the yield and purity of target exosomes. ${ }^{48,50}$ This method does not need to label exosomes, which can avoid cross-contamination, but it is not conducive to downstream analysis due to its time consumption, high cost, structural damage, aggregation into blocks, and lipoprotein co-separation. ${ }^{11,51}$

The purpose of density gradient centrifugation is to purify exosomes, and it is usually used in combination with ultracentrifugation to improve the purity of exosomes. There are two main types, one using sucrose as a medium, which is widely used in research. However, exosomes and retroviruses are extremely similar in terms of size and density, and the sucrose density gradient cannot effectively separate the two. At this point, Cantin et al. ${ }^{52}$ found that their sedimentation velocities in the iodixanol gradient is significantly different, which enabled the successful separation of exosomes from HIV-1infected cells and the harvest of high-purity exosomes. In contrast, the density gradient centrifugation has an advantage in exosome purity, but the high viscosity of sucrose solution will reduce the sedimentation rate of exosomes, resulting in a longer time. ${ }^{53}$

\section{Polymer Precipitation}

The method of polymer precipitation usually uses polyethylene glycol (PEG) as a medium, and the exosomes are harvested under the condition of centrifugation by reducing the solubility of the exosomes. This method was originally used to isolate viruses. ${ }^{54}$ Because exosomes and viruses have similar biophysical characteristics, this method is often used in scientific research to isolate and purify exosomes. Rider et al. ${ }^{55}$ compared three technologies of ultracentrifugation, modified polymer co-precipitation (ExtraPEG) and commercially available commercial kits, and found that the first two methods are better than the commercial method and that ExtraPEG is more cost effective, which surpasses ultracentrifugation in terms of purity and recovery. The polymer precipitation method is relatively easy to operate with short analysis time and is suitable for processing large doses of samples. However, the purity and recovery rate is relatively low and false positives may be generated, and the polymer produced is difficult to remove, which is not conducive to subsequent functional experimental analysis.

\section{Size-Based Isolation Techniques}

This technique mainly refers to ultrafiltration and size exclusion chromatography, which separates based on the size difference between exosomes and other components in biological samples.

The separation principle of size-exclusion chromatography (SEC) is that the macromolecules cannot enter the gel pores and that they are eluted along the gaps between the porous gels with the mobile phase, while the small molecules remain in the gel pores and are finally eluted by the mobile phase. At present, qEV separation columns, EVSecond purification columns, and Exo-spin exosome purification columns are commercially available based on the SEC principle. The application of SEC is quick, easy, and low-cost. The isolated exosomes have complete structure and uniform size, and their biological characteristics are not significantly adversely affected, but they may be doped with other particles of similar size, resulting in reduced purity. ${ }^{51}$

The method of ultrafiltration usually uses ultrafiltration membranes with different molecular weight cutoffs (MWCO) to selectively separate samples. The usage rate of this method is about $20 \%,{ }^{56}$ and it often plays a role in assisting separation in exosome research. The ultrafiltration method usually uses ultrafiltration tubes to separate 
exosomes with low cost and high enrichment efficiency and the activity of exosomes is not affected. However, there are problems with low purity and non-specific binding of exosomes and ultrafiltration membranes to reduce the recovery rate. ${ }^{57}$

\section{Immunoaffinity Chromatography (IAC)}

Immunoaffinity chromatography is a separation and purification technology based on the specific binding of antibodies and ligands to separate desired substances from heterogeneous mixtures. The binding efficiency is closely related to the biological affinity pairs, elution conditions and matrix carriers. In principle, the biomarkers (antigens) applied by this method should be high-abundance proteins on the surface of exosome membranes, such as four-transmembrane protein superfamily, ESCRT complex-related proteins. Of course, the target protein can be a common component on the surface of exosomes, or the unique one that promotes IAC to recognize specific cellderived exosomes. Compared to ultracentrifugation, IAC can produce comparable results with less sample volume. It also can be used for qualitative and quantitative determination of exosomes. It has strong specificity, high sensitivity, high purity and high yield, and does not set the upper limit of the starting sample volume when based on magnetic beads. ${ }^{16,58,59}$ For example, the enzyme-linked immunosorbent analysis technique based on microplates is used to enrich exosomes in fluids such as serum, plasma and urine. Quantitative detection and analysis found that the yield of exosomes harvested by this method is equivalent to that of ultracentrifugation, but the demand of samples is much smaller. The amount of RNA extracted from $400 \mu \mathrm{L}$ plasma is the same as the amount obtained by ultracentrifugation of $2.5 \mathrm{~mL}$ samples, so there are certain advantages over ultracentrifugation. ${ }^{60}$ Nevertheless, the storage conditions of exosomes obtained by immunoaffinity chromatography are relatively harsh and are not suitable for large-scale separation of exosomes. The nonspecific interference adsorption of the matrix will produce interfering proteins, making this method difficult to popularize.

\section{Other Isolation Techniques}

There are various commercial kits currently on the market based on the above traditional isolation technology, like exoEasy Maxi kit (QIAGEN), MagCapture ${ }^{\mathrm{TM}}$ Exosome Isolation Kit PS (Wako) and Minute ${ }^{\mathrm{TM}}$ Hi-Efficiency Exosome Precipitation Reagent (Invent). Comprehensive analysis shows that the commercial kit has the advantages of time saving, high yield, good integrity and so on. However, due to the uneven extraction effect of the current commercial exosome extraction kits, there is still no kit that can isolation the ideal exosomes from the mixture of samples. At the same time, the kit itself is expensive, and the yield and purity of exosomes are not high. But with the continuous exploration, development and innovation of exosome isolation and purification technology, more and more new methods are available for researchers to optimize traditional technologies from one or more perspectives, which has potential application value.

A recent study has developed a new micro-vortex chip, which is integrated with Morpho Menelaus butterfly wings modified with lipid nanoprobes to solve the problem of difficulty in effectively separating and purifying extracellular vesicles from biological fluids. When the body fluid passes through this chip, the generated micro vortices can enhance the interaction force between the extracellular vesicles and butterfly wings, and at the same time, the probe is inserted into the extracellular vesicles to achieve high-throughput enrichment. After testing, it is found that the separation efficiency of this technology exceeds $70 \%$ and does not affect downstream analysis, which has potential application value ${ }^{61}$. Salivaderived exosomes are separated and purified based on the size using a newly developed acoustic fluid platform, which combined acoustics with microfluidic technology. The average yield of small RNA in exosomes detected by RT-ddPCR using this technique is 15 times that of differential centrifugation, and studies have found that harvesting exosomes by this technique is beneficial for downstream analysis ${ }^{62}$. In addition, separation techniques such as Tangential Flow Filtration, ${ }^{63}$ Flow fieldflow fractionation (FIFFF) ${ }^{64}$ and Deterministic lateral displacement array ${ }^{65}$ also have good enrichment potential.

Although a variety of methods for the isolation and purification of exosomes have been developed, there are some shortcomings that cannot meet all needs. The combination of different isolation methods may be better than the separation effect of a single method. Therefore, in order to improve the separation efficiency and enrichment, and thus obtain the ideal exosomes, many research teams have begun to combine multiple methods to isolate and purify the exosomes to improve the yield and purity. For example, by combining ultracentrifugation and ultrafiltration to extract exosomes crudely, and then using magnetic beads to adsorb affinity bodies containing colonic epithelial cell-specific A33 antibody by immunoaffinity capture technology to further purify the exosomes. Various exosomal proteins associated with colon cancer have been identified as potential diagnostic biomarkers. ${ }^{66}$ To make up for the deficiencies of the kit based on polymer precipitation method, the research team tried to combine $\mathrm{UC}$ with the kit to extract exosomes from human serum. The experiment found 
that this combination scheme can provide better yield and quality assurance, suitable for further study with large samples to meet the clinical application standard. ${ }^{67}$ Koh et al. ${ }^{68}$ combined UC with SEC, which could not only handle largevolume of samples, but also effectively eliminate the interference of contaminants, so as to draw on each other's merits. This not only reduced the separation time, but also increased the yield, which was suitable for enriching exosomes from biofluids.

\section{Characterization}

The exosome characterization is specific and identical, so several characterization indexes are needed to determine whether the extracted components are exosomes. International Society for Extracellular Vesicles (ISEV) proposed $^{10}$ that two types of proteins (like Transmembrane or GPI-anchored proteins associated to plasma membrane and/ or endosomes, Cytosolic proteins recovered in $\mathrm{EVs}$ ) need to be evaluated to determine whether the extracted components are exosomes and exosomes derived from biological fluids can be assessed for their purity by determining the presence or absence of certain non-EV structural protein components coseparated with EV. In general research, we consider the identification of isolated exosomes from three levels, including TEM identification of exosome morphology, NTA identification of exosome size and Western Blot identification of exosome surface protein markers. Exosome characterization methods are mainly divided into two types: external characterization (mainly morphology and particle size detection) and inclusion characterization (like membrane protein, lipid raft). The purpose, advantages and disadvantages of commonly applied methods are shown in Table 1.

Recently, some characterization methods developed and optimized at home and abroad are available for reference. For example, Islam et al. $^{74}$ provided a way to measure EVs without extensive pretreatment. The NP-TRFIA technology uses biotinylated antibodies that specifically target four transmembrane proteins and tumor-associated antigens to capture EVs from urine and cell supernatants directly, and then the performances of two lanthanidebased tracers are compared for detection and characterization. The signal-to-noise ratio of this method is 2-10 times that of the lectin-chelate assay. Compared with Western blot and flow cytometry, it simplifies the separation step and saves time. At the same time, it can be used to identify and evaluate tumor-associated proteins on the surface of $\mathrm{EVs}$, and has potential for disease diagnosis and prognosis. In addition to marker proteins, specific types of phospholipids present in the lipid bilayer may also be a potential positive control for characterizing the presence of exosomes, ${ }^{75,76}$ so it may be considered to develop multiple markers to characterize exosomes in many ways.

\section{Storage Stability}

Exosomes are a promising cell-free therapy, but they cannot be stored for a long time. Therefore, it is necessary to study exosomes preservation technology to protect their biological activities and make them convenient for transportation and clinical application. Currently, the applied protection techniques mainly include freezing, freeze-drying and spray-drying.

\section{Cryopreservation}

Cryopreservation is a storage method that reduces the temperature below the temperature required for biochemical reactions to maintain the functional stability of the biological particles, and is usually applied at the temperature of $4{ }^{\circ} \mathrm{C},-80{ }^{\circ} \mathrm{C}$ and $-196^{\circ} \mathrm{C}$. However, this storage method is prone to "frostbite". The "frostbite" described here is mostly related to the imbalance of osmosis during the freezing process and the formation of ice crystals inside the biological particles. In order to overcome this deficiency, one or more antifreezes with appropriate concentrations are often added selectively to extend the shelf life. $^{77-79}$

Antifreeze is usually divided into two types of permeability and non-permeability. Among them, the permeable antifreeze has a small molecular weight and can penetrate the cell membrane into the cell to prevent the formation of ice crystals, such as dimethyl sulfoxide and ethylene glycol. Studies have shown that from a morphological perspective, direct freezing affects the stability of exosomal membranes and promotes their degradation, while DMSO-added exosomes in cryopreservation are similar to fresh exosomes. Moreover, in terms of biological activity, Short-term cryopreservation (within 2 months) did not significantly change the function of exosomes. ${ }^{70}$ Non-permeable antifreeze can form hydrogen bonds with water, usually trehalose, sucrose and other carbohydrates. Sugar replaces the water molecules around the lipid head group through the interaction between the phospholipid head group and the $\mathrm{OH}$ part of the sugar. The glass matrix of the sugar can prevent the aggregation of vesicles and reduce the damage caused by ice crystals. ${ }^{80}$ Considering the safety, the disaccharide antifreeze is the best choice for exosomes, among which trehalose is listed as the most effective disaccharide antifreeze. ${ }^{81}$ It is worth noting that the appropriate concentration of antifreeze should 
Table I Purpose, Advantages and Disadvantages of Common Exosome Characterization Methods

\begin{tabular}{|c|c|c|c|}
\hline Methods & Purpose & Advantages & Disadvantages \\
\hline $\begin{array}{l}\text { Electron microscope (Scanning } \\
\text { electron microscope SEM or } \\
\text { Transmission electron } \\
\text { microscope TEM) }\end{array}$ & $\begin{array}{l}\text { Detection of } \\
\text { exosomal } \\
\text { morphology }\end{array}$ & $\begin{array}{l}\text { Electron microscope can directly observe the } \\
\text { morphological structure of exosomes, among } \\
\text { which SEM can observe the surface structure, } \\
\text { TEM can observe the internal structure and } \\
\text { provide the information of particle size } \\
\text { distribution. }\end{array}$ & $\begin{array}{l}\text { Due to the complicated operation of TEM } \\
\text { and higher requirements on sample } \\
\text { preparation than SEM, it is not suitable for } \\
\text { rapid measurement of a large number of } \\
\text { samples. }{ }^{70} \text { SEM's resolution is lower than } \\
\text { TEM. }\end{array}$ \\
\hline $\begin{array}{l}\text { Dynamic light scattering } \\
\text { technology }\end{array}$ & $\begin{array}{l}\text { Detecting the } \\
\text { size of exosomes }\end{array}$ & $\begin{array}{l}\text { The lower limit of measurement is } 10 \mathrm{~nm} \text {, } \\
\text { which is suitable for the determination of } \\
\text { monodisperse systems. }\end{array}$ & $\begin{array}{l}\text { It is not suitable for measuring complex } \\
\text { exosome samples with large size range, } \\
\text { the concentration of exosomes cannot be } \\
\text { detected, and it is difficult to distinguish } \\
\text { contaminated proteins from exosomes. }\end{array}$ \\
\hline $\begin{array}{l}\text { Nanoparticle Tracking Analysis } \\
\text { Technology (NTA) }\end{array}$ & $\begin{array}{l}\text { Detecting the } \\
\text { size and } \\
\text { concentration of } \\
\text { exosomes }\end{array}$ & $\begin{array}{l}\text { The detection speed is fast and the exosomes } \\
\text { can be observed in real time. The resolution is } \\
\text { higher than the flow cytometer, and the lower } \\
\text { limit of the measurement of fluorescent } \\
\text { particles can reach } 30-40 \mathrm{~nm} \text {. }\end{array}$ & $\begin{array}{l}\text { The operation is complicated and it is } \\
\text { difficult to distinguish contaminated } \\
\text { proteins from exosomes. Camera levels } \\
\text { and detection thresholds will affect the } \\
\text { quantification of exosomes. }\end{array}$ \\
\hline $\begin{array}{l}\text { Western Blot } \\
\text { (WB) }\end{array}$ & $\begin{array}{l}\text { Detection of the } \\
\text { expression of } \\
\text { exosomal } \\
\text { marker proteins }\end{array}$ & $\begin{array}{l}\text { As one of the classic methods, this technique } \\
\text { is mature and can qualitatively and } \\
\text { quantitatively analyze marker proteins. It is } \\
\text { also easier to analyze exosomes from cell } \\
\text { culture media. }\end{array}$ & $\begin{array}{l}\text { The operation is complicated and time- } \\
\text { consuming. The detection of marker } \\
\text { proteins varies depending on the type of } \\
\text { parental cell, and it is not suitable for the } \\
\text { detection of exosomal marker proteins in } \\
\text { biological fluids. }^{10}\end{array}$ \\
\hline $\begin{array}{l}\text { Enzyme-linked immunosorbent } \\
\text { analysis (ELISA) }\end{array}$ & $\begin{array}{l}\text { Detection of the } \\
\text { expression of } \\
\text { exosomal } \\
\text { marker proteins }\end{array}$ & $\begin{array}{l}\text { It has strong specificity and rapid detection, } \\
\text { can qualitatively and quantitatively analyze } \\
\text { marker proteins, and is suitable for high- } \\
\text { throughput analysis. }^{72}\end{array}$ & $\begin{array}{l}\text { The operation is complicated and time- } \\
\text { consuming. The repeatability is not good } \\
\text { and there are many interference factors. }\end{array}$ \\
\hline Flow Cytometry & $\begin{array}{l}\text { Detection of } \\
\text { biomarkers of } \\
\text { exosomes }\end{array}$ & $\begin{array}{l}\text { This method is capable of high-throughput, } \\
\text { multi-channel analysis, and the analysis speed } \\
\text { is fast, and the required sample concentration } \\
\text { is low. }\end{array}$ & $\begin{array}{l}\text { This technique is time-consuming and } \\
\text { laborious. The detection limit is } 400 \mathrm{~nm} \text {, } \\
\text { and the particle size of exosomes cannot } \\
\text { be measured. In addition, due to the } \\
\text { detection of optical signals, the accuracy } \\
\text { and resolution are relatively low, and the } \\
\text { characteristics of polydispersity and low } \\
\text { refraction limit its application. }{ }^{73}\end{array}$ \\
\hline
\end{tabular}

be examined before use to maintain a balanced state and prevent unnecessary injury.

\section{Freeze-Drying}

Freeze-drying is a technology that cools materials containing moisture in advance and freezes to a solid below freezing point, directly sublimates the ice under vacuum and removes it in the form of water vapor, thus meeting the storage requirements. Freeze-drying technology is mainly divided into three stages: pre-freezing stage, sublimation drying stage and analytical drying stage. The freeze-dried exosomal lyophilized powder can effectively reduce the storage conditions. Because it completes the dehydration and drying of products under low temperature and vacuum conditions, it can maintain its original activity and reduce the damage to biological tissues and cell bodies. The material can be easily kept in a constant storable state, and can be reconstituted by simply adding water. It is a suitable method for preserving heat-sensitive materials such as EVs, vaccines, and proteins.

During the freeze-drying process, the molecular structure of the biomolecule may be destroyed due to the freezing and dehydration pressures generated. Therefore, it is also necessary to selectively add antifreezes to protect the biological material. Charoenviriyakul et al. ${ }^{82}$ divided 
the exosomes from B16BL6 melanoma into three parts, one of which was stored at $-80^{\circ} \mathrm{C}$, one of which was freeze-dried with trehalose added, and one of which was freeze-dried directly, and compared the morphology, protein content and the influence on pharmacokinetics of the exosomes. The results show that the addition of trehalose can effectively prevent the aggregation of exosomes during the freeze-drying process, increase its colloidal stability, and do not change the morphology of exosomes. The protein content of lyophilized exosomes stored at room temperature was similar to that at $-80^{\circ} \mathrm{C}$, and the effect on pharmacokinetics was minimal.

\section{Spray-Drying}

Spray drying is a technique applied systematically to the drying of materials. After the EVs solution is atomized in the drying room, the moisture quickly vaporizes in contact with the hot air to obtain dry powders. During the process, the atomization pressure and outlet temperature are factors that affect the stability of exosomes. Compared with lyophilization, spray drying is a continuous process, which can realize one-step milling, which is more economical, and is expandable and can adjust the particle size of products. ${ }^{79}$

To date, the best comprehensive storage way is $-80{ }^{\circ} \mathrm{C}$ frozen storage. However, different sources and different experimental techniques all affect the temperature selection of long-term storage stability of exosomes. Studies have found that compared with freshly extracted exosomes, storage at $-80{ }^{\circ} \mathrm{C}$ for 4 days will change the morphology of exosomes, ${ }^{83}$ and the biological activity of exosomes will be reduced during storage at $-80{ }^{\circ} \mathrm{C}$ for 28 days. ${ }^{84}$ At the same time, some studies have shown that milk-derived exosomes are stored at $-80{ }^{\circ} \mathrm{C}$ for four weeks without any change in physical properties, and the loading rate of paclitaxel also remains stable. ${ }^{35}$ Therefore, it is urgent to study the storage stability of exosomes from multiple perspectives, especially the long-term stability. For example, from the perspective of source, drug delivery route, application technology and future research direction. In short, it is beneficial to carry out subsequent functional studies of exosomes, shorten the experimental process and expand their application scope.

\section{Applications \\ Disease Diagnosis}

Exosomes are rich in biomarkers for disease diagnosis and prognosis. They are mainly applied in cancer and have also made some progress in the fields of cardiovascular diseases, tuberculosis and central nervous system diseases. The level of exosomal microRNAs associated with cardiovascular diseases including miR-499, miR-133, miR-208, miR-192, miR-194, miRNA-34a is up-regulated in patients with acute myocardial infarction and heart failure, ${ }^{85-88}$ which provides a strong basis for their use as a diagnostic marker. It is reported that Dysferlinopathy is a kind of disease caused by the lack of dysferlin. Yin's team ${ }^{89}$ evaluated the diagnostic ability of exosomes in the serum and urine of patients with this disease, and found that there is no dysferlin in exosomes from patients, which can be distinguished from normal people for the diagnosis of Dysferlinopathy. MiR-21, miR-29, miR-219, LRP6, REST1, caveolin1 in exosomes are differentially expressed in central nervous system diseases, showing good clinical diagnostic potential. ${ }^{90-93}$

Liquid biopsy is a minimally invasive, convenient and fast diagnostic method in vitro for tumor sampling. Tumor exosomes can promote tumor formation in the process of normal cell carcinogenesis. They are highly enriched in biofluids and can be used for liquid biopsy. Because the expression of biologically active substances carried by exosomes in healthy people and tumor patients is different, the detection of biomarkers that predict cancer in tumor exosomes can help improve the specificity and sensitivity of early diagnosis of tumors. For example, exosomal protein CD151 is highly expressed in patients with lung cancer, ${ }^{94}$ miR-1246 and miR-21 are highly enriched in exosomes derived from breast cancer cells, ${ }^{95}$ and miR638 can be used as a diagnostic marker for colorectal cancer. ${ }^{96}$ Exosomal miRNA is the most commonly used biomarker with tissue specificity. Studies have found that exosomes are rich in miRNA, and the membrane structure of exosomes can enhance the stability of miRNA molecules and enhance their potential as disease biomarkers. In 2016, Exosome Diagnostics launched the world's first cancer diagnostic product-ExoDX Lung (ALK). The product is based on exosomal detection technology, which can simultaneously detect exosomal RNA and ctDNA, and perform real-time screening for EML4-ALK mutations in patients with non-small cell lung cancer. According to data provided by Exosome Diagnostics, ExoDx Lung (ALK) has a sensitivity of $88 \%$ and a specificity of $100 \%$ in detecting non-small cell lung cancer, which can be used to assist doctors in determining whether patients are suitable for ALK inhibitor targeted therapy, especially for those patients who are unable or unwilling to undergo tissue biopsy. 


\section{Disease Treatment Through Exosome- Targeted Drug Delivery System}

Exosomes are small in size, which can effectively avoid the phagocytosis of mononuclear macrophages, and can freely cross the blood vessel wall and extracellular matrix. The expression of CD55 and CD59 on its surface avoids the activation of opsonin and coagulation factors, so it can be widely distributed and stable in the biofluids. Compared to liposomes and other nano-delivery systems which are synthesized in vitro, exosomes originate from the body, and have better biocompatibility and lower immunogenicity in theory. In fact, due to the heterogeneity of exosomes, they carry various proteins on the surface, which enter the cells in a variety of ways after contacting with cells. Among them, receptormediated endocytosis is one of the main ways of information communication between exosomes and target tissues, which optimizes the endocytosis process of exosomes and promotes the internalization of the encapsulated drug and facilitates the continuous and stable transport of the contents in the blood with high transport efficiency. Moreover, exosomes have strong ability to homing target tissues or cells and penetrate biological barriers (like the blood-brain barrier), so they have the advantage of natural drug delivery and are promising targeted drug carriers, which can be used to deliver genetic drugs, traditional Chinese medicine, western medicine, and so on. ${ }^{97,98}$ However, natural exosomes may have problems such as weak targeting and susceptible to be quickly cleared in the body, resulting in poor treatment effect. At this time, they are usually modified to form engineered exosomes. Engineered exosomes refer to natural exosomes loaded with therapeutic agents or modified. In the following part, the applications of targeted delivery system of exosomes will be explained mainly from the perspectives of drug loading and surface modification.

\section{Type of Drug Loading}

Western medicine is one of the therapeutic agents delivered by exosomes as drug carriers, which can play a role in various pathological processes such as cancer and inflammation. The mortality rate of cancer has been high for a long time, and it is the goal of research teams at home and abroad to develop efficient cancer treatment strategies. Doxorubicin is an amphiphilic drug, which can inhibit angiogenesis and control tumor growth to play a therapeutic role. It belongs to a broad-spectrum antitumor drug. Yang et al. ${ }^{99}$ used the zebrafish model to examine the efficacy of brain endothelial-derived exosomes to deliver the anti-tumor drug doxorubicin through the blood-brain barrier. The image shows that exosomes successfully loaded the drug across the blood-brain barrier, which can significantly inhibit the growth of tumors, confirming that exosomes can act as a carrier. In addition, anti-cancer drugs such as porphyrin, ${ }^{100}$ tirapazamine, ${ }^{101}$ docetaxel and cisplatin can also exert their effects through exosomes.

Catalase (CAT) is one of the most effective antioxidants. It can inhibit inflammation and protect dopaminergic neurons. It can be used to treat neurodegenerative diseases. Neurodegenerative diseases are caused by the loss of neurons and/or their myelin sheaths and are generally diagnosed based on clinical symptoms. The presence of the blood-brain barrier (BBB) limits the application of nearly $98 \%$ of central nervous system disease treatment agents, and clinical application is extremely difficult. ${ }^{102}$ Chronic diseases require long-term drug treatment ${ }^{103,104}$. When investigating the therapeutic effect of CAT on Parkinson's disease, Haney et al. ${ }^{105}$ found that encapsulation of CAT with exosomes can effectively reduce oxidative stress and increase the survival rate of neurons in both in vivo and in vitro models of PD. At the same time, loading CAT on exosomes can maintain its biological activity, reduce immunogenicity, prolong blood circulation time, and solve its deficiencies of easy inactivation and rapid degradation, thereby enhancing the therapeutic effect. In summary, Exo-CAT preparation is expected to become a general strategy for the treatment of neurodegenerative diseases.

Traditional Chinese medicines, including monomeric active ingredients and compound preparations, have been widely used in the study of exosome delivery systems due to its low toxicity and side effects.

Although paclitaxel (PTX) is a widely used antitumor drug, which can play a therapeutic role in a variety of malignant tumors, ${ }^{35}$ it is a highly hydrophobic compound and has dose-dependent toxic and side effects, so its clinical application is limited. ${ }^{106,107}$ Recently, studies using exosomal delivery of PTX to address this deficiency have been widely reported. For example, Wang et al. ${ }^{108}$ selected classical activated M1-type macrophage-derived exosomes as a carrier to reduce the toxicity of PTX and improve its bioavailability. Not only has PTX been successfully delivered to tumor tissue of mice, but also by activating NF- $\mathrm{KB}$ pathway it establishes a pro-inflammatory environment to enhance the therapeutic effect of PTX.

Curcumin is a lipophilic polyphenolic compound. Its low solubility, poor stability, fast metabolism, short half-life and other defects lead to lower bioavailability, which limits its application in the treatment of diseases. Sun et al. ${ }^{109}$ loaded curcumin onto exosomes to form a complex that enhanced its 
anti-inflammatory activity by improving the solubility, stability and bioavailability of curcumin. Mice treated with this complex were able to resist lipopolysaccharide (LPS)-induced septic shock. In addition, curcumin also has anti-tumor, antioxidation, anti-atherosclerosis and other effects.

Exosomes loaded with berry anthocyanins have good inhibitory activity against the proliferation of ovarian cancer cells. ${ }^{110}$ Exosomes carrying catalpol can play a neuroprotective role. ${ }^{111} \beta$-elemene-loaded exosomes can inhibit the proliferation and migration of tumor cells and also have a certain improvement in drug resistance to cancer cells. ${ }^{112,113}$ In addition, exosomes can also be loaded with triptolide $^{114}$ or the traditional Chinese medicine compound Buyanghuanwu Decoction ${ }^{115}$ to make up for the lack of single administration and enhance the therapeutic effect.

Exosomes can also deliver gene therapeutic agents such as DNA and RNA and adopt gene therapy strategies. For example, oligonucleotides can silence specific genes to treat a variety of human diseases, including cancer or neurodegenerative diseases. Oligonucleotide agent (ONT) is a kind of new drugs that prevents the expression of proteins that cause disease phenotypes by targeting RNA or DNA, such as delivering exosomes loaded with hydrophobic siRNAs (hsiRNAs) which target Huntingtin mRNA to the brain is an effective treatment for Huntington's disease and other neurodegenerative diseases ${ }^{116}$. Similarly, exosomes can carry therapeutic RNA to target cells, such as targeting exogenous siRNA to monocytes and lymphocytes in human blood cells, which can cause MAPK1 gene to silence selectively. ${ }^{117}$

\section{Route of Administration}

The exosome delivery system has various routes of administration, among which the common routes include intravenous injection, ${ }^{118,119}$ subcutaneous injection, ${ }^{120}$ intraperitoneal injection, ${ }^{121,122}$ intratumoral injection, ${ }^{123}$ nasal administration ${ }^{32,105,124,125}$ and oral administration. ${ }^{35}$ Essentially, the route of drug administration is closely related to the therapeutic effect of various diseases, and different routes of drug administration also affect the biological distribution and rapid clearance rate of drugs in vivo. Therefore, it is necessary to investigate the influence of the routes of exosome drug delivery system.

\section{Drug Loading Ways}

According to whether the therapeutic agent is directly loaded on the exosomes, it is mainly divided into two major drug loading types: pre-secretory drug loading and post-secretory drug loading. Pre-secretory drug loading means that the therapeutic agent originates from or is loaded on the parent cell to secrete engineered exosomes. This type of operation is simple, but the drug loading efficiency cannot be controlled, and the natural physiological function of membrane proteins may be damaged. As the name implies, post-secretory drug loading refers to the direct addition of therapeutic agents to exosomes in a certain way, but exosome aggregation, membrane damage and low yield may exist ${ }^{101,126,127}$. Electroporation and ultrasonic treatment are the most commonly used methods of drug loading because of their relative convenience and efficiency. The drug loading rate of exosomes may be related to the hydrophobicity of drugs, the drug loading method, the lipid composition of exosomes, etc. ${ }^{100}$. Therefore, in the actual study, the appropriate drug loading method is mainly selected according to the physical or chemical characteristics of the drugs and the common method is shown in Figure 2.

The method of gene editing uses genetically modified parent cells as the main strategy to integrate the therapeutic agent into the corresponding exosomes, and is suitable for RNA or proteins that cannot be directly loaded onto exosomes. Sterzenbach et al. ${ }^{124}$ used the L-domain-containing protein Ndfp1 to recognize the WW-tagged target protein Cre recombinase, thereby loading the target protein into exosomes during MVB formation. Flow cytometry showed that the WW tag did not affect Cre recombinase activity. Such exosomes can cross the blood-brain barrier to deliver bioactive proteins, providing a new strategy for the treatment of brain diseases. In another study, FAM miR-125a was used to transfect human adiposederived MSCs, and miR-125a overexpressed exosomes were obtained. It was found that miR-125a in exosomes plays a key role in endothelial cell angiogenesis ${ }^{128}$. There are also commercial transfection reagents on the market, like HiPerFect transfection reagent and Lipofectamine 2000, to load siRNA directly into exosomes. However, it is clear that this method is relatively inefficient in loading and relatively complicated to operate. Therefore, Li et al. ${ }^{129}$ constructed a CD9-HuR fusion protein, in which HuR is an RNA-binding protein located inside the exosomes, and selectively enriched the target miR155 into the exosomes. This method does not destroy RNA structure, has a strong ability to enrich specific RNAs, significantly improves loading efficiency, and is expected to become a new strategy for clinical trials of gene delivery in vivo.

There are two forms of co-incubation. One is to coincubate the therapeutic agent with parental cells to disperse the therapeutic agent or to load part of the therapeutic agent in the cytoplasm into the secreted exosomes by means of endocytosis by parental cells. The other is that 
exosomes and therapeutic agents are directly co-incubated and mixed under appropriate conditions. Their loading efficiency mainly depends on the concentration gradient of the drug in the solution and its hydrophobicity. The hydrophobic drugs with high concentration usually have relatively high loading efficiency. ${ }^{105}$ The method is easy to operate, highly reproducible, and does not affect the integrity of exosome membrane structure, but the loading efficiency is low, and a large number of therapeutic agents are needed. It is also necessary to investigate whether the therapeutic agents have toxic side effects on parental cells and affect the stability by changing the surface charge of exosomes.

Electroporation is to expose the suspension of exosomes and therapeutic agents to the electric field. The exosome membranes will produce temporary pores under a short high-voltage pulse, so the therapeutic agents will penetrate into the exosomes. Electroporation is a relatively mature method, which is simple and time-saving, and can be used to load nucleotides, doxorubicin and other drugs into exosomes ${ }^{130}$. The exosomal concentration will affect the efficiency of electroporation. Wahlgren et al. ${ }^{117}$ used exosomes from peripheral blood as carriers to deliver therapeutic siRNA by electroporation. In the experiment, the effects of exosomal concentration,
siRNA concentration and electroporation parameters on the efficiency of electroporation were investigated. It was found that changes in siRNA and capacitance did not affect the electroporation efficiency, and the electroporation efficiency was the highest when the exosome concentration was within the range of $0.25-1 \mathrm{mg} / \mathrm{mL}$. However, this method also has disadvantages, such as destroying the integrity of the membrane structure, reducing the loading efficiency and low loading rate. The use of high-voltage pulses will cause exosomes to aggregate. At the same time, this method may destroy the protein structure and affect its activity, which limits its application.

Sonication is highly efficient in drug loading and can sustainably release drugs, especially hydrophobic drugs, and can prevent protease destruction. However, this method may lead to aggregation of exosomes and affect their immune activity, which not only requires high requirements on the instrument, but also may damage the plasma membrane structure of exosomes and cause drug leakage, resulting in unsatisfactory drug loading. Sonication may alter the high rigidity of the membrane, and recombination of exosomal membranes results in high loading efficiency and sustained drug release. Kim et al. ${ }^{32}$ compared the loading rates of the three loading methods of co-incubation, electroporation and

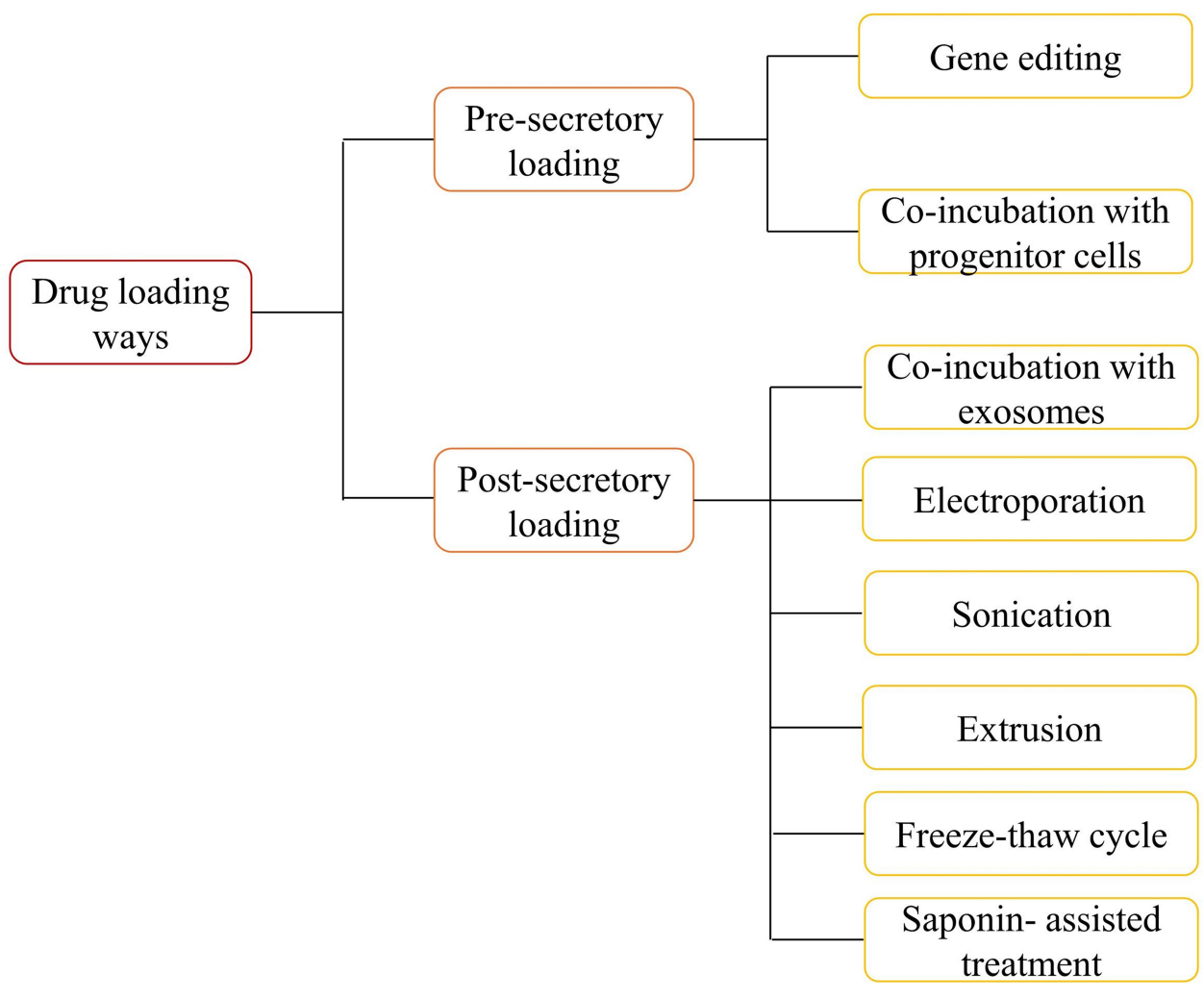

Figure 2 Common drug loading ways of exosomes. 
sonication, and the results showed that the load capacity of exosomes treated by sonication was the highest, confirming the above hypothesis. Similarly, Salarpour et al. ${ }^{131}$ investigated the effects of $37^{\circ} \mathrm{C}$ co-incubation and sonication on the encapsulation efficiency of PTX (hydrophobic drugs), and found that the loading of sonication $(9.21 \pm 0.41 \mathrm{ng} / \mu \mathrm{g})$ was higher than that of co-incubation $(7.40 \pm 0.37 \mathrm{ng} / \mu \mathrm{g})$, which gave similar results to Kim.

Extrusion usually uses an extruder to achieve drug loading of exosomes. During the extrusion process, the exosomal membrane is broken and violently mixed with therapeutic agents. ${ }^{132}$ The method of extrusion can obtain higher drug loading. For example, compared with co-incubation and freeze-thaw cycles, exosomes loaded with catalase (CAT) by extrusion have the highest encapsulation rate and show strong catalytic activity. Therefore, such exosomes provide the most effective neuroprotective effect, which is due to the remodeling of exosomal membranes by extrusion so that CAT diffuses through the relatively tight and highly structured lipid bilayer, thus resulting in a high encapsulation rate. ${ }^{105}$ However, it may damage the plasma membrane structure of exosomes and cause drug leakage. Whether cytotoxicity will be produced remains to be studied.

The freeze-thaw cycle is a physical and chemical process that simply mixes exosomes with drugs and freezes at $-80 \circ \mathrm{C}$ or liquid nitrogen, and then thaws at room temperature. $^{132,133}$ The drug loading capacity of the freeze-thaw cycle is usually lower than that of sonication and extrusion. Exosomes may aggregate and cause an increase in size. In addition, proteins are also easily degraded to affect biological activity.

In the process of the Saponin-assisted treatment, saponin is an effective permeabilizing agent for the cytoplasmic membrane. It selectively forms a complex with cholesterol bound to exosomal membranes to form a porous structure on the membrane surface, which promotes the incorporation of therapeutic agents. Studies have found that saponin-treated exosomes loaded with ProBA [mesoTetra(4-carboxyphenyl) porphine] have a high drug loading rate, and the drug intake is about $8 \%$, which is significantly higher than that of free drugs $(2 \%)$, so it can be shown that saponin-assisted treatment enhances the loading of porphyrins in exosomes without affecting the drug delivery capacity. ${ }^{100}$ However, saponins are a class of surfactants that are hemolytic in vivo, so the concentration of saponins needs to be limited, and exosomes should be washed and purified immediately after coincubation. $^{132,134}$
In summary, the above methods do not allow the combination of therapeutic agents with different properties to be loaded simultaneously, whether the pre-secretory loading or the post-secretory loading. Lee et al. ${ }^{101}$ applied liposomes to the surface modification of extracellular vesicles. MFL (membrane-fused liposomes) can effectively co-load a lipophilic drug (Paclitaxel) and a hydrophilic drug (Tirapazamine) into extracellular vesicles simultaneously, without affecting the original functional expression of membrane proteins. Thus, it can be considered as a general strategy. In short, no matter which method is adopted in practical application, factors such as drug properties, drug loading, efficiency, damage to exosome membranes, and influence on subsequent experiments should be considered comprehensively to find the best method.

\section{Surface Modification}

Surface modification is the process of treating exosomal surface proteins as anchoring devices or affinity tags, and modifying the protein or peptide components that meet the requirements to the particle surface by certain means. Natural exosomes need to be superficially modified if they are unable to effectively deliver drugs or targeted applications due to their inadequacy, such as poor stability and rapid elimination. ${ }^{29}$ One of the biggest advantages of exosomes is endogenous, which can avoid causing adverse manifestations such as immune response. However, the efficiency of exosomal delivery is affected by parental cells and receptor cells. The yield of exosomes from different sources is significantly different, and natural exosomes have the problem with poor-targeting. In order to meet the experimental needs, surface modification to manufacture engineered exosomes is a way of practical application value. Surface functionalization of exosomes with targeted ligands can help them be selectively delivered to target cells and enable exosomes to reach standards in terms of yield and targeted therapy, so as to achieve precise treatment of exosomes and accelerate the clinical application of exosomes.

In order to precisely target therapeutic drugs to the lesion, the methods commonly used in recent years include chemical linking of targeting peptides, modification of exosomal membranes or progenitor cells by genetic engineering, magnetic nanoparticle technology, electrostatic interaction and post-insertion. Applications of partial surface modification exosomes are listed in Table 2.

There is no doubt that surface-modified exosomes have certain advantages, but engineering exosomes also have certain limitations. First, surface modification of exosomes cannot change the structure and surface molecules of exosomes, 
Table 2 Application Examples of Surface Modification

\begin{tabular}{|c|c|c|c|c|}
\hline $\begin{array}{l}\text { Surface } \\
\text { Modification } \\
\text { Methods }\end{array}$ & Targeting Method & Drug Loading & $\begin{array}{l}\text { Targeted Tissues and } \\
\text { Applications }\end{array}$ & Ref. \\
\hline $\begin{array}{l}\text { Genetic } \\
\text { Engineering }\end{array}$ & $\begin{array}{l}\text { Dendritic cells (DCs) are genetically modified to express } \\
\text { fusion proteins containing the membrane protein } \\
\text { Lamp } 2 b \text { and RVG peptides, and engineered exosomes } \\
\text { are harvested from the cells. }\end{array}$ & $\begin{array}{l}\text { siRNA } \\
\text { (Electroporation) }\end{array}$ & $\begin{array}{l}\text { Targeting the central nervous system } \\
\text { (neurons, microglia, } \\
\text { oligodendrocytes) to treat } \\
\text { Alzheimer's disease }\end{array}$ & [126] \\
\hline $\begin{array}{l}\text { Chemical } \\
\text { reaction } \\
\text { combined with } \\
\text { post-insertion }\end{array}$ & $\begin{array}{l}\text { c (RGDyK) is a tumor-targeting peptide. DSPE-PEG } \\
2000-c R G D y K \text { is prepared by chemical reaction. The } \\
\text { ligand is spontaneously inserted into the exosomal lipid } \\
\text { bilayer through hydrophobic interactions and combined } \\
\text { to obtain the targeted exosomes. }\end{array}$ & $\begin{array}{l}\text { PTX } \\
\text { (Co-incubation) }\end{array}$ & $\begin{array}{l}\text { It can penetrate the blood-brain } \\
\text { barrier, target glioblastomas, and } \\
\text { significantly } \\
\text { reduce the activity of cancer cells. }\end{array}$ & [135] \\
\hline $\begin{array}{l}\text { Genetic } \\
\text { Engineering }\end{array}$ & $\begin{array}{l}\text { Donor cells are engineered to express the } \\
\text { transmembrane domain of the platelet-derived growth } \\
\text { factor receptor fused to the GEII peptide to achieve } \\
\text { targeting, thereby assimilating exosomes from this } \\
\text { source. }\end{array}$ & $\begin{array}{l}\text { let-7a miRNA } \\
\text { (Transfection) }\end{array}$ & $\begin{array}{l}\text { Targeting breast cancer tissues } \\
\text { expressing EGFR to treat breast } \\
\text { cancer }\end{array}$ & [136] \\
\hline $\begin{array}{l}\text { Genetic } \\
\text { Engineering }\end{array}$ & $\begin{array}{l}\text { Engineered mouse immature dendritic cells expressing } \\
\text { Lamp2b fused to iRGD peptide to produce tumor- } \\
\text { targeted exosomes. }\end{array}$ & $\begin{array}{l}\text { DOX } \\
\text { (Electroporation) }\end{array}$ & $\begin{array}{l}\text { It targets tumor tissues, inhibits the } \\
\text { growth of tumor, and has good } \\
\text { antitumor activity. }\end{array}$ & {$[119]$} \\
\hline $\begin{array}{l}\text { Chemical } \\
\text { reaction }\end{array}$ & $\begin{array}{l}\text { Extracellular vesicles containing azide lipids were firstly } \\
\text { prepared and then conjugated to the targeted peptide } \\
\text { using a copper-free catalytic click chemistry. }\end{array}$ & $\begin{array}{l}\text { PTX, TPZ } \\
\text { (Loaded on } \\
\text { liposomes) }\end{array}$ & Targeting tumor cells & {$[101]$} \\
\hline $\begin{array}{l}\text { Electrostatic } \\
\text { interaction }\end{array}$ & $\begin{array}{l}\text { The complex formed by a cationic lipid and a pH- } \\
\text { sensitive fusion peptide binds exosomes through } \\
\text { electrostatic interaction to target the receptor cell } \\
\text { membrane. }\end{array}$ & $\begin{array}{l}\text { Dextran, Saponin } \\
\text { (Electroporation) }\end{array}$ & $\begin{array}{l}\text { Targeting the receptor's cell } \\
\text { membrane to enhance cell uptake } \\
\text { and cytoplasmic release of exosomes }\end{array}$ & [137] \\
\hline $\begin{array}{l}\text { Magnetic } \\
\text { nanoparticle } \\
\text { technology }\end{array}$ & $\begin{array}{l}\text { The SPMN-Tf conjugates were co-incubated with pre- } \\
\text { dialyzed serum to form SMNC-Exo through interaction } \\
\text { with the Tf-Tf receptor. After drug loading, SMNC-Exos } \\
\text { were concentrated in the tumor region in the presence } \\
\text { of an external magnetic field. }\end{array}$ & $\begin{array}{l}\text { DOX } \\
\text { (Co-incubation) }\end{array}$ & $\begin{array}{l}\text { Targeting mouse subcutaneous } \mathrm{H} 22 \\
\text { cells to inhibit the growth of tumor }\end{array}$ & [138] \\
\hline
\end{tabular}

while chemically linked targeting peptides have the potential to alter the surface structure of exosomes. Furthermore, the operation of genetically modified parental cells is complex, and the transfection efficiency is low, which is easy to affect the original biological activity of membrane proteins. When exosomes are modified with virus-derived proteins (or peptides), it is necessary to evaluate whether there is an adverse reaction to themselves. In addition, cationic nanomaterials used in electrostatic interactions may cause cytotoxicity and the loading efficiency is relatively low.

Based on the limitations of the popular surface modification methods currently, professor Yin's team screened out the phage CP05 coupled targeting molecules (M12, RVG, SP94) to form a chimeric peptide, and then combined them with
CD63 on the exosomal surface to capture exosomes from different sources. The method has a high modification efficiency. Not only is the amount of exosomes caught large, but also the targeting can be enhanced, so that the modified exosomes can be enriched respectively in muscle, brain and subcutaneous tumors. CP05-modified exosomes have not changed significantly in their physiological characteristics, have not changed the structure and surface molecules of exosomes, and are expected to be used for rapid detection of clinical cancer and effective carriers for therapeutic drugs. ${ }^{139}$ In addition, Tamura et al. ${ }^{140}$ used cationized amylopectin to modify the exosomes to make them have the ability to target the asialoglycoprotein receptor of hepatocytes, which helps to achieve precise treatment of exosomes and enhance treatment 
effect. Lee et al. ${ }^{101}$ also optimized the method of chemically linking and targeting peptides. The parent cells were treated with azide-MFL to generate azide-EVs, which were then linked with the tumor-targeting peptide conjugate DBCOCGKPK through a biological orthogonal reaction. In this process, DBCO- CGKPK uses copper-free catalytic click chemistry to connect. Such engineered EVs can be used to load therapeutic agents internally and externally can be modified with multiple functions. Exogenous incorporation of MFL for surface modification does not affect membrane proteins that play a decisive role in the biological function of EVs.

Engineered exosomes do not have absolute advantages in drug delivery applications. Some studies have found that the same loading method is used to load cholesterolmodified siRNA to prepare engineered exosomes and anionic fusion liposomes respectively to compare their delivery capabilities. Engineered exosomes cannot functionally deliver relevant small RNAs, while anionic fusion liposomes can induce siRNA-mediated knockout of target genes. ${ }^{141}$ Therefore, when considering whether to apply engineered exosomes, it is necessary to combine with the actual situation and have a deep understanding of the molecular transfer mechanism and specificity, and blind application should be avoided by all means.

\section{Conclusions}

Compared with liposomes, nanoparticles, microspheres, microemulsions and other synthetic drug loading systems, the endogeneity of exosomes is a natural and unique advantage. The superiority of exosomes makes it an important medium for cell-to-cell communication, and it plays unique biological functions in regulating the normal life activities and in the diagnosis and treatment of diseases. Exosomes, as current research hotspots, have received extensive attention from researchers at home and abroad. However, the detection technologies for the diagnosis and prognosis of diseases using exosomal contents as markers have not been perfected. Whether exosomes can be used clinically as soon as possible depends largely on the results of optimization and improvement of the existing exosome problems. How to improve the yield and purity of exosomes is the top priority, which has always been the bottleneck limiting its transformation application. Studies in recent years have shown that the appropriate combination of several methods to extract and purify exosomes can effectively improve the above problems, and how to combine them to achieve the best results remains to be further studied. Secondly, the secretion mechanism and fusion mechanism of exosomes are still unclear. The impact of exosome heterogeneity on drug loading efficiency needs to be further revealed. Exosome loading capacity and methods for enhancing targeting also need to be optimized and improved. Carry out all-round and multi-field researches to analyze its biological functions and lay the foundation for subsequent pharmacokinetics, toxicology research, and clinical testing, which will help to better understand the state of the body and diagnose and treat diseases in the future.

\section{Funding}

This work was supported by the National Natural Science Foundation of China (81803738).

\section{Disclosure}

The authors have declared that there is no conflict of interest.

\section{References}

1. Thery C, Zitvogel L, Amigorena S. Exosomes: composition, biogenesis and function. Nat Rev Immunol. 2002;2(8):569-579. doi: $10.1038 /$ nri855

2. Simons M, Raposo G. Exosomes-vesicular carriers for intercellular communication. Curr Opin Cell Biol. 2009;21(4):575-581. doi:10.1016/j.ceb.2009.03.007

3. Pluchino S, Smith JA. Explicating exosomes: reclassifying the rising stars of intercellular communication. Cell. 2019;177 (2):225-227. doi:10.1016/j.cell.2019.03.020

4. Willms E, Johansson HJ, Mager I, et al. Cells release subpopulations of exosomes with distinct molecular and biological properties. Sci Rep. 2016;6(1):22519. doi:10.1038/srep22519

5. Farooqi AA, Desai NN, Qureshi MZ, et al. Exosome biogenesis, bioactivities and functions as new delivery systems of natural compounds. Biotechnol Adv. 2018;36(1):328-334. doi:10.1016/j. biotechadv.2017.12.010

6. Trams EG, Lauter CJ, Salem N Jr, Heine U. Exfoliation of membrane ecto-enzymes in the form of micro-vesicles. Biochim Biophys Acta. 1981;645(1):63-70. doi:10.1016/0005-2736(81) 90512-5

7. Harding C, Heuser J, Stahl P. Receptor-mediated endocytosis of transferrin and recycling of the transferrin receptor in rat reticulocytes. J Cell Biol. 1983;97(2):329-339. doi:10.1083/ jcb.97.2.329

8. Pan B-T, Johnstone RM. Fate of the transferrin receptor during maturation of sheep reticulocytes in vitro: selective externalization of the receptor. Cell. 1983;33(3):967-978. doi:10.1016/00928674(83)90040-5

9. Johnstone RM. The Jeanne Manery-Fisher Memorial Lecture 1991. Maturation of reticulocytes: formation of exosomes as a mechanism for shedding membrane proteins. Biochem Cell Biol. 1992;70(3-4):179-190. doi:10.1139/092-028

10. Thery C, Witwer KW, Aikawa E, et al. Minimal information for studies of extracellular vesicles 2018 (MISEV2018): a position statement of the International Society for Extracellular Vesicles and update of the MISEV2014 guidelines. J Extracell Vesicles. 2018;7(1):1535750.

11. Yang XX, Sun C, Wang L, Guo XL. New insight into isolation, identification techniques and medical applications of exosomes. $J$ Control Release. 2019;308:119-129. doi:10.1016/j.jconrel.20 19.07.021 
12. Jeppesen DK, Fenix AM, Franklin JL, et al. Reassessment of exosome composition. Cell. 2019;177(2):428-445e418. doi:10.1016/j.cell.2019.02.029

13. Gatti S, Bruno S, Deregibus MC, et al. Microvesicles derived from human adult mesenchymal stem cells protect against ischaemia-reperfusion-induced acute and chronic kidney injury. Nephrol Dial Transplant. 2011;26(5):1474-1483. doi:10.1093/ndt/gfr015

14. Henne WM, Buchkovich NJ, Emr SD. The ESCRT pathway. Dev Cell. 2011;21(1):77-91. doi:10.1016/j.devcel.2011.05.015

15. Trajkovic K, Hsu C, Chiantia S, et al. Ceramide triggers budding of exosome vesicles into multivesicular endosomes. Science. 2008;319(5867):1244-1247. doi:10.1126/science.1153124

16. Tschuschke M, Kocherova I, Bryja A, et al. Inclusion biogenesis, methods of isolation and clinical application of human cellular exosomes. J Clin Med. 2020;9(2):436. doi:10.3390/jcm9020436

17. Rana S, Zoller M. Exosome target cell selection and the importance of exosomal tetraspanins: a hypothesis. Biochem Soc Trans. 2011;39(2):559-562. doi:10.1042/BST0390559

18. de Gassart A, Geminard C, Fevrier B, Raposo G, Vidal M. Lipid raft-associated protein sorting in exosomes. Blood. 2003;102 (13):4336-4344. doi:10.1182/blood-2003-03-0871

19. Cheng L, Zhang K, Wu SY, Cui MH, Xu TM. Focus on mesenchymal stem cell-derived exosomes: opportunities and challenges in cell-free therapy. Stem Cells Int. 2017;2017:1-10. doi:10.1155/ 2017/6305295

20. He CQ, Hua W, Liu JT, Fan LL, Wang H, Sun GP. Exosomes derived from endoplasmic reticulum-stressed liver cancer cells enhance the expression of cytokines in macrophages via the STAT3 signaling pathway. Oncol Lett. 2020;20(1):589-600. doi:10.3892/ol.2020.11609

21. Li DP, Wang Y, Jin XR, et al. NK cell-derived exosomes carry miR-207 and alleviate depression-like symptoms in mice. $J$ Neuroinflammation. 2020;17(1). doi:10.1186/s12974-020-01 787-4.

22. Zhao DY, Yu ZC, Li Y, Wang Y, Li QF, Han D. GelMA combined with sustained release of HUVECs derived exosomes for promoting cutaneous wound healing and facilitating skin regeneration. J Mol Histol. 2020;51(3):251-263. doi:10.1007/ s10735-020-09877-6

23. Pascucci L, Cocce V, Bonomi A, et al. Paclitaxel is incorporated by mesenchymal stromal cells and released in exosomes that inhibit in vitro tumor growth: a new approach for drug delivery. J Control Release. 2014;192:262-270. doi:10.1016/j.jconrel.20 14.07.042

24. Yin S, Ji C, Wu P, Jin C, Qian H. Human umbilical cord mesenchymal stem cells and exosomes: bioactive ways of tissue injury repair. Am J Transl Res. 2019;11(3):1230-1240.

25. Zhang B, Wang M, Gong A, et al. HucMSC-exosome mediatedWnt4 signaling is required for cutaneous wound healing. Stem Cells. 2015;33(7):2158-2168. doi:10.1002/stem.1771

26. Arslan F, Lai RC, Smeets MB, et al. Mesenchymal stem cellderived exosomes increase ATP levels, decrease oxidative stress and activate PI3K/Akt pathway to enhance myocardial viability and prevent adverse remodeling after myocardial ischemia/reperfusion injury. Stem Cell Res. 2013;10(3):301-312. doi:10.1016/j. scr.2013.01.002

27. Liu L, Jin X, Hu CF, Li R, Zhou Z, Shen CX. Exosomes derived from mesenchymal stem cells rescue myocardial ischaemia/reperfusion injury by inducing cardiomyocyte autophagy via AMPK and Akt pathways. Cell Physiol Biochem. 2017;43(1):52-68. doi: $10.1159 / 000480317$

28. Cui GH, Wu J, Mou FF, et al. Exosomes derived from hypoxiapreconditioned mesenchymal stromal cells ameliorate cognitive decline by rescuing synaptic dysfunction and regulating inflammatory responses in APP/PS1 mice. FASEB J. 2018;32(2):654668. doi:10.1096/fj.201700600R
29. Antimisiaris SG, Mourtas S, Marazioti A. Exosomes and exosome-inspired vesicles for targeted drug delivery. Pharmaceutics. 2018;10(4):218. doi:10.3390/pharmaceutics10040218

30. Yan B, Liu QB, Liu G, et al. Macrophage-derived exosomes mediate osteosarcoma cell behavior by activating AKT signaling. RSC Adv. 2020;10(9):5032-5039. doi:10.1039/C9RA07332A

31. Yuan ZH, Petree JR, Lee FEH, et al. Macrophages exposed to HIV viral protein disrupt lung epithelial cell integrity and mitochondrial bioenergetics via exosomal microRNA shuttling. Cell Death Dis. 2019;10.

32. Kim MS, Haney MJ, Zhao Y, et al. Development of exosome-encapsulated paclitaxel to overcome MDR in cancer cells. Nanomedicine. 2016;12(3):655-664. doi:10.1016/j.nano.2015.10.012

33. Kalluri R, LeBleu VS. The biology, function, and biomedical applications of exosomes. Science. 2020;367(6478):6478. doi:10.1126/science.aau6977

34. Kanchanapally R, Deshmukh SK, Chavva SR, et al. Drug-loaded exosomal preparations from different cell types exhibit distinctive loading capability, yield, and antitumor efficacies: a comparative analysis. Int J Nanomedicine. 2019;14:531-541. doi:10.2147/IJN. S191313

35. Agrawal AK, Aqil F, Jeyabalan J, et al. Milk-derived exosomes for oral delivery of paclitaxel. Nanomedicine. 2017;13(5):16271636. doi:10.1016/j.nano.2017.03.001

36. Zhuo CJ, Hou WH, Jiang DG, et al. Circular RNAs in early brain development and their influence and clinical significance in neuropsychiatric disorders. Neural Regen Res. 2020;15(5):817-823. doi:10.4103/1673-5374.268969

37. Shaimardanova AA, Solovyeva VV, Chulpanova DS, James V, Kitaeva KV, Rizvanov AA. Extracellular vesicles in the diagnosis and treatment of central nervous system diseases. Neural Regen Res. 2020;15(4):586-596. doi:10.4103/1673-5374.266908

38. Srivastava A, Moxley K, Ruskin R, Dhanasekaran DN, Zhao YD, Ramesh R. A non-invasive liquid biopsy screening of urine-derived exosomes for miRNAs as biomarkers in endometrial cancer patients. AAPS J. 2018;20(5):82. doi:10.1208/s12248-018-0220-y

39. Poggio M, Hu T, Pai -C-C, et al. Suppression of exosomal PD-L1 induces systemic anti-tumor immunity and memory. Cell. 2019;177(2):414. doi:10.1016/j.cell.2019.02.016

40. Sanderson RD, Bandari SK, Vlodaysky I. Proteases and glycosidases on the surface of exosomes: newly discovered mechanisms for extracellular remodeling. Matrix Biol. 2019;75-76:160-169. doi:10.1016/j.matbio.2017.10.007

41. Bernardi S, Foroni C, Zanaglio C, et al. Feasibility of tumorderived exosome enrichment in the onco-hematology leukemic model of chronic myeloid leukemia. Int J Mol Med. 2019;44 (6):2133-2144. doi:10.3892/ijmm.2019.4372

42. Zlotogorski A, Vered M, Chaushu G, Dayan D. Exosomes isolated from saliva of cancer patients differ from those of healthy individuals. Oral Oncol. 2013;49:S70-S71. doi:10.1016/j. oraloncology.2013.03.185

43. Wu BR, Sun DL, Ma LJ, et al. Exosomes isolated from CAPS1overexpressing colorectal cancer cells promote cell migration. Oncol Rep. 2019;42(6):2528-2536. doi:10.3892/or.2019.7361

44. Mu J, Zhuang $\mathrm{X}$, Wang $\mathrm{Q}$, et al. Interspecies communication between plant and mouse gut host cells through edible plant derived exosome-like nanoparticles. Mol Nutr Food Res. 2014;58(7):1561-1573. doi:10.1002/mnfr.201300729

45. Yang C, Zhang M, Merlin D. Advances in plant-derived edible nanoparticle-based lipid nano-drug delivery systems as therapeutic nanomedicines. J Mater Chem B. 2018;6(9):1312-1321. doi:10.1039/C7TB03207B

46. Zhang M, Viennois E, Xu C, Merlin D. Plant derived edible nanoparticles as a new therapeutic approach against diseases. Tissue Barriers. 2016;4(2):e1134415. doi:10.1080/21688370.2 015.1134415 
47. Zhuang X, Deng ZB, Mu J, et al. Ginger-derived nanoparticles protect against alcohol-induced liver damage. J Extracell Vesicles. 2015;4(1):28713. doi:10.3402/jev.v4.28713

48. Livshits MA, Khomyakova E, Evtushenko EG, et al. Isolation of exosomes by differential centrifugation: theoretical analysis of a commonly used protocol. Sci Rep. 2015;5(1):17319. doi:10.1038/ srep 17319

49. Clotilde Théry AS, Raposo G, Amigorena S, et al. Isolation and characterization of exosomes from cell culture supernatants and biological fluids. Curr Protoc Stem Cell Biol. 2006;30(1).

50. Cvjetkovic A, Lotvall J, Lasser C. The influence of rotor type and centrifugation time on the yield and purity of extracellular vesicles. $J$ Extracell Vesicles. 2014;3(1):23111. doi:10.3402/jev.v3.23111

51. Boing AN, van der Pol E, Grootemaat AE, Coumans FA, Sturk A, Nieuwland R. Single-step isolation of extracellular vesicles by size-exclusion chromatography. J Extracell Vesicles. 2014;3 (1):23430. doi:10.3402/jev.v3.23430

52. Cantin R, Diou J, Belanger D, Tremblay AM, Gilbert C. Discrimination between exosomes and HIV-1: purification of both vesicles from cell-free supernatants. J Immunol Methods. 2008;338(1-2):21-30. doi:10.1016/j.jim.2008.07.007

53. Ford T, Graham J, Rickwood D. Iodixanol: a nonionic iso-osmotic centrifugation medium for the formation of self-generated gradients. Anal Biochem. 1994;220(2):360-366. doi:10.1006/ abio.1994.1350

54. Oh DK, Hyun CK, Kim JH, Park YH. Production of penicillin in a fluidized-bed bioreactor: control of cell growth and penicillin production by phosphate limitation. Biotechnol Bioeng. 1988;32 (4):569-573. doi:10.1002/bit.260320421

55. Rider MA, Hurwitz SN, Meckes DG Jr. ExtraPEG: a polyethylene glycol-based method for enrichment of extracellular vesicles. Sci Rep. 2016;6(1):23978. doi:10.1038/srep23978

56. Consortium E-T, Van Deun J, Mestdagh P, et al. EV-TRACK: transparent reporting and centralizing knowledge in extracellular vesicle research. Nat Methods. 2017;14(3):228-232. doi:10.1038/ nmeth. 4185

57. Vergauwen G, Dhondt B, Van Deun J, et al. Confounding factors of ultrafiltration and protein analysis in extracellular vesicle research. Sci Rep. 2017;7(1):2704. doi:10.1038/s41598-017-02599-y

58. Fitzgerald J, Leonard P, Darcy E, Sharma S, O’Kennedy R. Immunoaffinity chromatography: concepts and applications. Methods Mol Biol. 2017;1485:27-51.

59. Li P, Kaslan M, Lee SH, Yao J, Gao Z. Progress in exosome isolation techniques. Theranostics. 2017;7(3):789-804. doi: $10.7150 /$ thno. 18133

60. Zarovni N, Corrado A, Guazzi P, et al. Integrated isolation and quantitative analysis of exosome shuttled proteins and nucleic acids using immunocapture approaches. Methods. 2015;87:4658. doi:10.1016/j.ymeth.2015.05.028

61. Han S, Xu Y, Sun J, et al. Isolation and analysis of extracellular vesicles in a morpho butterfly wing-integrated microvortex biochip. Biosens Bioelectron. 2020;154:112073. doi:10.1016/j. bios.2020.112073

62. Wang Z, Li F, Rufo J, et al. Acoustofluidic salivary exosome isolation: a liquid biopsy compatible approach for human papillomavirus-associated oropharyngeal cancer detection. $J \mathrm{Mol}$ Diagn. 2020;22(1):50-59. doi:10.1016/j.jmoldx.2019.08.004

63. Heinemann ML, Ilmer M, Silva LP, et al. Benchtop isolation and characterization of functional exosomes by sequential filtration. $J$ Chromatogr A. 2014;1371:125-135. doi:10.1016/j. chroma.2014.10.026

64. Yang JS, Lee JC, Byeon SK, Rha KH, Moon MH. Size dependent lipidomic analysis of urinary exosomes from patients with prostate cancer by flow field-flow fractionation and nanoflow liquid chromatography-tandem mass spectrometry. Anal Chem. 2017;89 (4):2488-2496. doi:10.1021/acs.analchem.6b04634
65. Wunsch BH, Smith JT, Gifford SM, et al. Nanoscale lateral displacement arrays for the separation of exosomes and colloids down to $20 \mathrm{~nm}$. Nat Nanotechnol. 2016;11(11):936-940. doi:10.1038/nnano.2016.134

66. Mathivanan S, Lim JW, Tauro BJ, Ji H, Moritz RL, Simpson RJ. Proteomics analysis of A33 immunoaffinity-purified exosomes released from the human colon tumor cell line LIM1215 reveals a tissue-specific protein signature. Mol Cell Proteomics. 2010;9 (2):197-208. doi:10.1074/mcp.M900152-MCP200

67. Ryu KJ, Lee JY, Park C, Cho D, Kim SJ. Isolation of small extracellular vesicles from human serum using a combination of ultracentrifugation with polymer-based precipitation. Ann Lab Med. 2020;40(3):253-258. doi:10.3343/alm.2020.40.3.253

68. Koh YQ, Almughlliq FB, Vaswani K, Peiris HN, Mitchell MD. Exosome enrichment by ultracentrifugation and size exclusion chromatography. Front Biosci (Landmark Ed). 2018;23(3):865874. doi: $10.2741 / 4621$

69. Pisitkun T, Shen RF, Knepper MA. Identification and proteomic profiling of exosomes in human urine. Proc Natl Acad Sci U S A. 2004;101(36):13368-13373. doi:10.1073/pnas.0403453101

70. Wu Y, Deng W, Klinke D. Exosomes: improved methods to characterize their morphology, RNA content, and surface protein biomarkers. Analyst. 2015;140(19):6631-6642. doi:10.1039/C5AN00688K

71. Maas SL, de Vrij J, van der Vlist EJ, et al. Possibilities and limitations of current technologies for quantification of biological extracellular vesicles and synthetic mimics. J Control Release. 2015;200:87-96. doi:10.1016/j.jconrel.2014.12.041

72. Shao H, Im H, Castro CM, Breakefield X, Weissleder R, Lee H. New technologies for analysis of extracellular vesicles. Chem Rev. 2018;118(4):1917-1950. doi:10.1021/acs.chemrev.7b00534

73. Pospichalova V, Svoboda J, Dave Z, et al. Simplified protocol for flow cytometry analysis of fluorescently labeled exosomes and microvesicles using dedicated flow cytometer. $J$ Extracell Vesicles. 2015;4(1):25530. doi:10.3402/jev.v4.25530

74. Islam MK, Syed P, Lehtinen L, et al. A nanoparticle-based approach for the detection of extracellular vesicles. Sci Rep. 2019;9(1):10038. doi:10.1038/s41598-019-46395-2

75. Record M, Carayon K, Poirot M, Silvente-Poirot S. Exosomes as new vesicular lipid transporters involved in cell-cell communication and various pathophysiologies. Biochim Biophys Acta. 2014;1841(1):108-120. doi:10.1016/j.bbalip.2013.10.004

76. Skotland T, Sandvig K, Llorente A. Lipids in exosomes: current knowledge and the way forward. Prog Lipid Res. 2017;66:30-41. doi:10.1016/j.plipres.2017.03.001

77. Bahr MM, Amer MS, Abo-El-Sooud K, Abdallah AN, El-Tookhy OS. Preservation techniques of stem cells extracellular vesicles: a gate for manufacturing of clinical grade therapeutic extracellular vesicles and long-term clinical trials. Int J Vet Sci Med. 2020;8 (1):1-8. doi:10.1080/23144599.2019.1704992

78. Jeyaram A, Jay SM. Preservation and storage stability of extracellular vesicles for therapeutic applications. AAPS J. 2017;20 (1):1. doi:10.1208/s12248-017-0160-y

79. Kusuma GD, Barabadi M, Tan JL, Morton DAV, Frith JE, To LR. Protect and to preserve: novel preservation strategies for extracellular vesicles. Front Pharmacol. 2018;9:1199.

80. Abdelwahed W, Degobert G, Stainmesse S, Fessi H. Freeze-drying of nanoparticles: formulation, process and storage considerations. Adv Drug Deliv Rev. 2006;58(15):1688-1713. doi:10.1016/ j.addr.2006.09.017

81. Bosch S, de Beaurepaire L, Allard M, et al. Trehalose prevents aggregation of exosomes and cryodamage. Sci Rep. 2016;6 (1):36162. doi:10.1038/srep36162

82. Charoenviriyakul C, Takahashi Y, Nishikawa M, Takakura Y. Preservation of exosomes at room temperature using lyophilization. Int $J$ Pharm. 2018;553(1-2):1-7. doi:10.1016/j. ijpharm.2018.10.032 
83. Maroto R, Zhao Y, Jamaluddin M, et al. Effects of storage temperature on airway exosome integrity for diagnostic and functional analyses. $J$ Extracell Vesicles. 2017;6(1):1359478. doi:10.1080/20013078.2017.1359478

84. Lorincz AM, Timar CI, Marosvari KA, et al. Effect of storage on physical and functional properties of extracellular vesicles derived from neutrophilic granulocytes. J Extracell Vesicles 2014;3(1):25465. doi:10.3402/jev.v3.25465

85. Corsten MF, Dennert R, Jochems S, et al. Circulating MicroRNA208b and MicroRNA-499 reflect myocardial damage in cardiovascular disease. Circ Cardiovasc Genet. 2010;3(6):499-506. doi:10.1161/CIRCGENETICS.110.957415

86. Gidlof O, Andersson P, van der Pals J, Gotberg M, Erlinge D. Cardiospecific microRNA plasma levels correlate with troponin and cardiac function in patients with ST elevation myocardial infarction, are selectively dependent on renal elimination, and can be detected in urine samples. Cardiology. 2011;118(4):217226. doi:10.1159/000328869

87. Matsumoto S, Sakata Y, Suna S, et al. Circulating p53-responsive microRNAs are predictive indicators of heart failure after acute myocardial infarction. Circ Res. 2013;113(3):322-326. doi:10.1161/CIRCRESAHA.113.301209

88. Wang GK, Zhu JQ, Zhang JT, et al. Circulating microRNA: a novel potential biomarker for early diagnosis of acute myocardial infarction in humans. Eur Heart J. 2010;31(6):659-666. doi:10.1093/eurheartj/ehq013

89. Dong X, Gao X, Dai Y, Ran N, Yin H. Serum exosomes can restore cellular function in vitro and be used for diagnosis in dysferlinopathy. Theranostics. 2018;8(5):1243-1255. doi: $10.7150 /$ thno. 22856

90. Goetzl EJ, Boxer A, Schwartz JB, et al. Low neural exosomal levels of cellular survival factors in Alzheimer's disease. Ann Clin Transl Neurol. 2015;2(7):769-773. doi:10.1002/acn3.211

91. Kucharzewska P, Christianson HC, Welch JE, et al. Exosomes reflect the hypoxic status of glioma cells and mediate hypoxiadependent activation of vascular cells during tumor development. Proc Natl Acad Sci U S A. 2013;110(18):7312-7317. doi:10.1073/ pnas. 1220998110

92. Pusic AD, Kraig RP. Youth and environmental enrichment generate serum exosomes containing miR-219 that promote CNS myelination. Glia. 2014;62(2):284-299. doi:10.1002/glia.22606

93. Vella LJ, Hill AF, Cheng L. Focus on extracellular vesicles: exosomes and their role in protein trafficking and biomarker potential in alzheimer's and parkinson's disease. Int J Mol Sci. 2016;17(2):173. doi:10.3390/ijms17020173

94. Sandfeld-Paulsen B, Jakobsen KR, Baek R, et al. Exosomal proteins as diagnostic biomarkers in lung cancer. $J$ Thorac Oncol. 2016;11(10):1701-1710. doi:10.1016/j.jtho.2016.05.034

95. Hannafon BN, Trigoso YD, Calloway CL, et al. Plasma exosome microRNAs are indicative of breast cancer. Breast Cancer Res. 2016;18(1):90. doi:10.1186/s13058-016-0753-x

96. Yan S, Dang G, Zhang X, et al. Downregulation of circulating exosomal miR-638 predicts poor prognosis in colon cancer patients. Oncotarget. 2017;8(42):72220-72226. doi:10.18632/ oncotarget.19689

97. Irène Tatischeff AA. A new biological strategy for drug delivery: eucaryotic cell-derived nanovesicles. J Biomater Nanobiotechnol. 2011;2(5).

98. van den Boorn JG, Schlee M, Coch C, Hartmann G. SiRNA delivery with exosome nanoparticles. Nat Biotechnol. 2011;29 (4):325-326. doi:10.1038/nbt.1830

99. Yang T, Martin P, Fogarty B, et al. Exosome delivered anticancer drugs across the blood-brain barrier for brain cancer therapy in Danio rerio. Pharm Res. 2015;32(6):2003-2014. doi:10.1007/ s11095-014-1593-y
100. Fuhrmann G, Serio A, Mazo M, Nair R, Stevens MM. Active loading into extracellular vesicles significantly improves the cellular uptake and photodynamic effect of porphyrins. J Control Release. 2015;205:35-44. doi:10.1016/j.jconrel.2014.11.029

101. Lee J, Lee H, Goh U, et al. Cellular engineering with membrane fusogenic liposomes to produce functionalized extracellular vesicles. ACS Appl Mater Interfaces. 2016;8(11):6790-6795. doi:10.1021/acsami.6b01315

102. Agrawal M, Ajazuddin TDK, Saraf S, et al. Recent advancements in liposomes targeting strategies to cross blood-brain barrier (BBB) for the treatment of Alzheimer's disease. $J$ Control Release. 2017;260:61-77. doi:10.1016/j.jconrel.2017.05.019

103. Pardridge WM. Drug transport across the blood-brain barrier. $J$ Cereb Blood Flow Metab. 2012;32(11):1959-1972. doi:10.1038/ jcbfm.2012.126

104. Silva GA. Nanotechnology applications and approaches for neuroregeneration and drug delivery to the central nervous system. Ann N Y Acad Sci. 2010;1199(1):221-230. doi:10.1111/j.17496632.2009.05361.x

105. Haney MJ, Klyachko NL, Zhao Y, et al. Exosomes as drug delivery vehicles for Parkinson's disease therapy. J Control Release. 2015;207:18-30. doi:10.1016/j.jconrel.2015.03.033

106. Fu B, Wang N, Tan HY, Li S, Cheung F, Feng Y. Multi-component herbal products in the prevention and treatment of chemotherapy-associated toxicity and side effects: a review on experimental and clinical evidences. Front Pharmacol. 2018;9:1394. doi:10.3389/fphar.2018.01394

107. Oun R, Moussa YE, Wheate NJ. Correction: the side effects of platinum-based chemotherapy drugs: a review for chemists. Dalton Trans. 2018;47(23):7848. doi:10.1039/C8DT90088D

108. Wang P, Wang H, Huang Q, et al. Exosomes from M1-polarized macrophages enhance paclitaxel antitumor activity by activating macrophages-mediated inflammation. Theranostics. 2019;9 (6):1714-1727. doi:10.7150/thno.30716

109. Sun D, Zhuang X, Xiang X, et al. A novel nanoparticle drug delivery system: the anti-inflammatory activity of curcumin is enhanced when encapsulated in exosomes. Mol Ther. 2010;18 (9):1606-1614. doi:10.1038/mt.2010.105

110. Aqil F, Jeyabalan J, Agrawal AK, et al. Exosomal delivery of berry anthocyanidins for the management of ovarian cancer. Food Funct. 2017;8(11):4100-4107. doi:10.1039/C7FO00882A

111. Zhang XY, Zheng $\mathrm{H}$, Wang $\mathrm{YQ}$, et al. Protective effects of catalpol exosomes on damaged SH-SY5Y cells induced by low serum medium. Global Tradit Chin Med. 2017;10(2):155-158. doi:10.3969/j.issn.1674-1749.2017.02.006

112. Papa A, Wan L, Bonora M, et al. Cancer-associated PTEN mutants act in a dominant-negative manner to suppress PTEN protein function. Cell. 2014;157(3):595-610. doi:10.1016/j. cell.2014.03.027

113. Zhang J, Zhang HD, Yao YF, Zhong SL, Zhao JH, Tang JH. Betaelemene reverses chemoresistance of breast cancer cells by reducing resistance transmission via exosomes. Cell Physiol Biochem. 2015;36(6):2274-2286. doi:10.1159/000430191

114. Aqil F, Kausar H, Agrawal AK, et al. Exosomal formulation enhances therapeutic response of celastrol against lung cancer. Exp Mol Pathol. 2016;101(1):12-21. doi:10.1016/j. yexmp.2016.05.013

115. Yang J, Gao F, Zhang Y, Liu Y, Zhang D. Buyang huanwu decoction (BYHWD) enhances angiogenic effect of mesenchymal stem cell by upregulating VEGF expression after focal cerebral ischemia. J Mol Neurosci. 2015;56(4):898-906. doi:10.1007/ s12031-015-0539-0

116. Didiot MC, Hall LM, Coles AH, et al. Exosome-mediated delivery of hydrophobically modified siRNA for huntingtin mRNA silencing. Mol Ther. 2016;24(10):1836-1847. doi:10.1038/ mt.2016.126 
117. Wahlgren J, De LKT, Brisslert M, et al. Plasma exosomes can deliver exogenous short interfering RNA to monocytes and lymphocytes. Nucleic Acids Res. 2012;40(17):e130. doi:10.1093/nar/ gks463

118. Marcus ME, Leonard JN. FedExosomes: engineering therapeutic biological nanoparticles that truly deliver. Pharmaceuticals (Basel). 2013;6(5):659-680. doi:10.3390/ph6050659

119. Tian Y, Li S, Song J, et al. A doxorubicin delivery platform using engineered natural membrane vesicle exosomes for targeted tumor therapy. Biomaterials. 2014;35(7):2383-2390. doi:10.1016/j.biomaterials.2013.11.083

120. Yang G, Chen Q, Wen D, et al. A therapeutic microneedle patch made from hair-derived keratin for promoting hair regrowth. ACS Nano. 2019;13(4):4354-4360. doi:10.1021/acsnano.8b09573

121. Maremanda KP, Sundar IK, Rahman I. Protective role of mesenchymal stem cells and mesenchymal stem cell-derived exosomes in cigarette smoke-induced mitochondrial dysfunction in mice. Toxicol Appl Pharmacol. 2019;385:114788. doi:10.1016/j. taap.2019.114788

122. Sheller-Miller S, Choi K, Choi C, Menon R. Cyclic-recombinasereporter mouse model to determine exosome communication and function during pregnancy. Am J Obstet Gynecol. 2019;221 (5):502 e501-502 e512. doi:10.1016/j.ajog.2019.06.010

123. Mizrak A, Bolukbasi MF, Ozdener GB, et al. Genetically engineered microvesicles carrying suicide mRNA/protein inhibit schwannoma tumor growth. Mol Ther. 2013;21(1):101-108. doi:10.1038/mt.2012.161

124. Sterzenbach U, Putz U, Low LH, Silke J, Tan SS, Howitt J. Engineered exosomes as vehicles for biologically active proteins. Mol Ther. 2017;25(6):1269-1278. doi:10.1016/j. ymthe.2017.03.030

125. Zhuang X, Xiang X, Grizzle W, et al. Treatment of brain inflammatory diseases by delivering exosome encapsulated anti-inflammatory drugs from the nasal region to the brain. Mol Ther. 2011;19(10):1769-1779. doi:10.1038/mt.2011.164

126. Alvarez-Erviti L, Seow Y, Yin H, Betts C, Lakhal S, Wood MJ. Delivery of siRNA to the mouse brain by systemic injection of targeted exosomes. Nat Biotechnol. 2011;29(4):341-345. doi: $10.1038 /$ nbt. 1807

127. Hood JL, Scott MJ, Wickline SA. Maximizing exosome colloidal stability following electroporation. Anal Biochem. 2014;448:4149. doi:10.1016/j.ab.2013.12.001

128. Liang X, Zhang L, Wang S, Han Q, Zhao RC. Exosomes secreted by mesenchymal stem cells promote endothelial cell angiogenesis by transferring miR-125a. J Cell Sci. 2016;129(11):2182-2189. doi: $10.1242 /$ jcs. 170373

129. Li Z, Zhou X, Wei M, et al. In vitro and in vivo RNA inhibition by CD9-HuR functionalized exosomes encapsulated with miRNA or CRISPR/dCas9. Nano Lett. 2019;19(1):19-28. doi:10.1021/ acs.nanolett.8b02689
130. Zhang YF, Shi JB, Li C. Small extracellular vesicle loading systems in cancer therapy: current status and the way forward. Cytotherapy. 2019;21(11):1122-1136. doi:10.1016/j. jcyt.2019.10.002

131. Salarpour S, Forootanfar H, Pournamdari M, Ahmadi-Zeidabadi M, Esmaeeli M, Pardakhty A. Paclitaxel incorporated exosomes derived from glioblastoma cells: comparative study of two loading techniques. Daru. 2019;27(2):533-539. doi:10.1007/s40199019-00280-5

132. Luan X, Sansanaphongpricha K, Myers I, Chen H, Yuan H, Sun D. Engineering exosomes as refined biological nanoplatforms for drug delivery. Acta Pharmacol Sin. 2017;38(6):754-763. doi:10.1038/aps.2017.12

133. Sato YT, Umezaki K, Sawada S, et al. Engineering hybrid exosomes by membrane fusion with liposomes. Sci Rep. 2016;6 (1):21933. doi:10.1038/srep21933

134. Podolak I, Galanty A, Sobolewska D. Saponins as cytotoxic agents: a review. Phytochem Rev. 2010;9(3):425-474. doi:10.1007/s11101-010-9183-Z

135. Zhu Q, Ling X, Yang Y, et al. Embryonic stem cells-derived exosomes endowed with targeting properties as chemotherapeutics delivery vehicles for glioblastoma therapy. Adv Sci (Weinh). 2019;6(6):1801899. doi:10.1002/advs.201801899

136. Ohno S, Takanashi M, Sudo K, et al. Systemically injected exosomes targeted to EGFR deliver antitumor microRNA to breast cancer cells. Mol Ther. 2013;21(1):185-191. doi:10.1038/ mt.2012.180

137. Nakase I, Futaki S. Combined treatment with a $\mathrm{pH}$-sensitive fusogenic peptide and cationic lipids achieves enhanced cytosolic delivery of exosomes. Sci Rep. 2015;5(1):10112. doi:10.1038/ srep10112

138. Qi H, Liu C, Long L, et al. Blood exosomes endowed with magnetic and targeting properties for cancer therapy. ACS Nano. 2016;10(3):3323-3333. doi:10.1021/acsnano.5b06939

139. Gao X, Ran N, Dong X, et al. Anchor peptide captures, targets, and loads exosomes of diverse origins for diagnostics and therapy. Sci Transl Med. 2018;10(444):eaat0195. doi:10.1126/scitranslmed.aat0195

140. Tamura R, Uemoto S, Tabata Y. Augmented liver targeting of exosomes by surface modification with cationized pullulan. Acta Biomater. 2017;57:274-284. doi:10.1016/j.actbio.2017.05.013

141. Stremersch S, Vandenbroucke RE, Van Wonterghem E, Hendrix A, De Smedt SC, Raemdonck K. Comparing exosome-like vesicles with liposomes for the functional cellular delivery of small RNAs. J Control Release. 2016;232:51-61. doi:10.1016/j. jconrel.2016.04.005
International Journal of Nanomedicine

\section{Publish your work in this journal}

The International Journal of Nanomedicine is an international, peerreviewed journal focusing on the application of nanotechnology in diagnostics, therapeutics, and drug delivery systems throughout the biomedical field. This journal is indexed on PubMed Central, MedLine, CAS, SciSearch ${ }^{\mathbb{}}$, Current Contents ${ }^{\mathbb{R}} /$ Clinical Medicine,
Journal Citation Reports/Science Edition, EMBase, Scopus and the Elsevier Bibliographic databases. The manuscript management system is completely online and includes a very quick and fair peer-review system, which is all easy to use. Visit http://www.dovepress.com/ testimonials.php to read real quotes from published authors. 